\section{Effect of fluoridated water on dental caries and fluorosis in schoolchildren who use fluoridated dentifrice}

\author{
Mikaelle Claro Costa Silva (D1, Cacilda Castelo Branco Lima (1)1, \\ Marina de Deus Moura de Lima (1) Lúcia de Fátima Almeida de Deus \\ Moura (D1, Cinthia Pereira Machado Tabchoury (D2, Marcoeli Silva de \\ Moura (1)1.
}

\begin{abstract}
This cross-sectional study evaluated the prevalence and severity of dental caries and fluorosis in children and adolescents using fluoridated toothpaste, from areas with and without fluoridated water. Parents of 5-year-old children and 12-year-old adolescents from neighbourhoods that are supplied with and without fluoridated water answered questionnaires for determining socio-economic and demographic characteristics and habits related to oral health. The individuals were examined, and dental caries and fluorosis were measured by dmft/DMFT and TF indexes, respectively. Descriptive, bivariate and logistic regression analyses were performed $(p<0.05)$. Of 692 participants, $47.7 \%$ were 5 -year-olds and $52.3 \%$ were 12 -year-olds. The mean dmft/DMFT in the 5-year-olds/ 12-year-olds from Exposed and Not Exposed fluoridated water groups was $1.53( \pm 2.47)$ and $3.54( \pm 4.10) / 1.53$ $( \pm 1.81)$ and $3.54( \pm 3.82)$, respectively. Children $(0 \mathrm{R}=2.86,95 \% \mathrm{Cl}=1.71-$ $4.75)$ and adolescents $(\mathrm{OR}=1.95,95 \% \mathrm{Cl}=1.24-3.05)$, who did not consume fluoridated water, had greater caries experience. Among adolescents, there was an association between fluoridated water and the prevalence of very $\mathrm{mild} / \mathrm{mild}$ fluorosis $(\mathrm{OR}=5.45,95 \% \mathrm{Cl}: 3.23-9.19)$ and moderate fluorosis $(O R=11.11,95 \% \mathrm{Cl}=4.43-27.87)$. Children and adolescents, who consumed fluoridated water, presented lower prevalence and severity of dental caries compared to those who used only fluoridated toothpaste as the source of fluoride. There is an association between water fluoridation and very mild/mild and moderate fluorosis in adolescents.
\end{abstract}

\author{
${ }^{1}$ Department of Pathology and Dental Clinics, \\ Federal University of Piaui. Teresina, Piaui, \\ Brasil. \\ ${ }^{2}$ Department of Biosciences, Campinas \\ University, Piracicaba Faculty of Dentistry, \\ Piracicaba, São Paulo, Brasil.
}

Key Words: water fluoridation, toothpaste, dental caries, fluorosis

\title{
Introduction
}

The reduction of caries prevalence observed in the last decades is greatly attributed to the use of fluoride (1). Fluoridation of the public water supply reduces the occurrence of dental caries by $60 \%$ (2). With the availability of other sources of fluoride, such as mouthwash, gel and toothpaste, the difference in the occurrence of caries between individuals from fluoridated and non-fluoridated areas was reduced to $30 \%$ to $40 \%$ (3). However, no difference has been reported in some age groups $(4,5)$.

The use of fluoridated toothpaste has been pointed out as a factor that justifies the decline in caries prevalence in some countries where water fluoridation has never been adopted. Similar reductions in the experience of caries have been observed in countries that provide water fluoridation (6). On the other hand, the use of fluoridated toothpaste in areas with fluoridated public water has increased the occurrence of dental fluorosis (7), although there is no evidence that fluoride in water at optimal concentration causes any other systemic effects on humans (8).

All sources of fluoride act in the same way, reducing demineralization and enhancing dental remineralization. Nevertheless, brushing with toothpaste also promotes the removal or disorganization of the dental biofilm, a causal factor of dental caries (9). Due to the wide access that people have to fluoridated toothpastes nowadays and to the great acceptance of the local mechanism of action of fluoride, questions have been raised about the maintenance of water fluoridation (10).

The majority of the studies included in a Cochrane systematic review about the effects of water fluoridation on the prevention of dental caries and dental fluorosis were conducted prior to 1975 before the widespread use of fluoridated toothpaste (11). Hence there is a need for more studies that provide contemporary evidence on the necessity of fluoridation of the public water supply for populations exposed to fluoridated toothpastes. In addition, fluoridation of public water supply, as a health policy, requires studies that assess its efficiency. Therefore, this study acts as a measure of epidemiological surveillance. Thus, the objective of this study was to evaluate the experience and severity of dental caries 
and fluorosis in children and adolescents using fluoridated toothpaste, who are exposed or not to artificial fluoridated water.

\section{Methods}

Ethical aspects

This cross-sectional study was submitted and approved by the Research Ethics Committee of the Federal University of Piaui (Sentence 635131) and followed the guidelines of STROBE (Strengthening the Reporting of Observational Studies in Epidemiology).

\section{Sample selection}

The water fluoridation in Teresina, capital of the state of Piaui, located in the north-east region of Brazil, with an estimated population of 814,230 inhabitants, began in 1978 and was made using sodium fluorosilicate until 1985. From 1986 to 1997, fluoridation was discontinued (12). Since 1997, fluorosilicic acid has been used. The distribution of water occurs through storage in several reservoirs throughout the city. As some districts are not interconnected with the Water Treatment Station, these neighbourhoods are deprived of fluoridated water, and have tubular wells as the main source of public water supply.

In each of the four macroregions of the city of Teresina, two schools and two daycare centers were selected, one in a non-fluoridated neighborhood and another in a fluoridated neighbourhood. In the non-fluoridated water neighborhoods, a random selection was not possible because there was only one school / day care center in this area, so all five-year-old children and 12-year-old adolescents from the selected schools were invited to participate in this study. At fluoridated water neighborhoods, the school I day care center was selected at random as there were more schools and day care centers. In each school I day care center, the individuals were randomly selected and examined. The selected individuals, who met the inclusion criteria but whose parents did not consent, were substituted by other individuals from the random selection, until the $n$ calculated for the sample was reached. In both groups, only public system schools were included, in order to ensure similar groups with respect to socio-economic profile.

\section{Determination of the fluoride concentration}

For the fluoride concentration certification, water samples were collected from the drinking fountains of the selected schools. As the supply of fluoridated water or its absence affects the entire neighborhood, the water consumed at home and that consumed at school have the same source, once these scholars live near the schools they attend. The analysis was conducted in the Laboratory of the Postgraduate Program in Dentistry of the Federal University of Piaui, using the specific ion electrode (Orion model No. 96-09, Orion Research Inc., Cambridge, MA, USA) coupled to an analyzer (Orion Star A214, Orion Research Incorporated, Cambridge, MA, USA), previously calibrated with standards from 0.125 to $1.00 \mu \mathrm{g} \mathrm{F} / \mathrm{mL}$. All samples were analyzed in duplicate.

\section{Inclusion and exclusion criteria}

Inclusion criteria were to be aged five or 12 , to be born and have always resided in the same neighbourhood with access to a public water supply, use public water supply as the main source, both for drinking and cooking food and to be regularly enrolled in school. Exclusion criteria were the use of a fixed orthodontic appliance and/or teeth with amelogenesis imperfecta.

\section{Determination of groups}

The non-fluoridated water group (NFW) was formed by children and adolescents living in neighbourhoods not supplied with fluoridated water. The municipal elementary schools in these neighbourhoods were visited, and all 5-year-olds and 12-year-olds were invited to participate in the study by submitting the consent (for parents) and assent form (for adolescents). The fluoridated water group (FW) was formed by children and adolescents from neighbourhoods close to those mentioned above but supplied with fluoridated water, and also attending municipal elementary schools. The FW group had a similar number of participants to the NFW group.

\section{Data collection methods}

Data collection took place in two time points. Initially, questionnaires were presented to the parents or guardians, to determine socio-economic and demographic characteristics and information on sex, mother's educational level, and family income. The frequency of toothbrushing, the type and amount of 
toothpaste used by the person responsible for brushing, frequency of sugar ingestion and visits to the dentist were also investigated. The questionnaires presented to parents or guardians of 5-year-olds and 12-year-olds were similar. Next, the dental examination was carried out after supervised oral hygiene with a dental brush and fluoridated toothpaste. The examinations were performed by an examiner (kappa index for dental caries $=0.92$ and dental fluorosis $=0.90$ ) under natural light with the participant's head on the examiner's legs. A flat oral mirror (Golgran ${ }^{\circledR}$, São Paulo, Brazil) and IPC probe (Trinity ${ }^{\circledR}$, São Paulo, Brazil) were used. Examinations were performed from March to December 2016.

Dental caries was measured by DMFT (permanent dentition) and dmft (deciduous dentition) indexes. Dental fluorosis was determined by the Thylstrup-Fejerskov index (TF), which is graded from TF 0 (without fluorosis) to TF 9 (maximum fluorosis). TF 1-TF 2 was considered very mild/mild fluorosis and TF 3-TF 4 moderate fluorosis. In the deciduous dentition, maxillary incisors and maxillary canines were examined. In the permanent dentition, incisors, canines, and premolars (which are the teeth exposed in the smile) were examined. The teeth were isolated with cotton rolls (buccal and lingual) and examined for caries and need for treatment, then dried for $30 \mathrm{~s}$ using a triple syringe adapted to a portable compressor (SCHULZ ${ }^{\circledR}$, model MS 2.3 Air Plus Bivolt, Joinville, Santa Catarina, Brazil) to determine the TF index. At the end of the examination, the dental fluorosis of the examinee was classified with the highest TF degree diagnosed.

\section{Sample size calculation}

The sample size was calculated using the StatCalc program of Epi Info (version 6.04) and the formula: $n=\partial 2 . p q / e 2$, where $n$ is the sample to be calculated, $\partial$ is the $95 \%$ confidence level $(\partial=1.96)$, and $\mathrm{pq}$ is the percentage by which the phenomenon occurs (where the prevalence of caries at age 5 and 12 years was $56.7 \%$ (MS, 2012, maximum error of 5\% and with design effect of 1.7). Thus, a minimum sample size of at least 641 individuals was obtained. The sample was increased by $20 \%$ assuming possible losses, which resulted in a final sample of 770 individuals.

\section{Statistical analysis}

Data were processed in SPSS ${ }^{\circledR}$ version 20.0 (Statistical Package for the Social Science for Windows, Armonk, NY, USA: IBM Corp., 2011). For the verification of associations, chi-square test and t-test with a significance level of $5 \%$ were applied. For logistic regression, a bivariate analysis was performed using the chi-square test. In the regression analysis, all variables with a $p$ value less than or equal to 0.20 were included in the bivariate analysis. After establishing the final regression model adjusted for the variables associated with the result with a value less than or equal to 0.05, the Hosmer-Lemeshow and Deviance tests were performed to test the goodness / quality of the model fit.

\section{Results}

A total of $78(10.1 \%)$ of the 770 individuals invited to participate in this study were excluded for not being born in Teresina or not having always resided in the same neighbourhood, or not having access to public water supply. Therefore, 692 individuals participated in this study (response rate $=88.9 \%$ ), of whom 330 (47.6\%) were 5-year-olds and $362(52.4 \%)$ were 12-year-olds.

The water collected from the non-fluoridated neighbourhood had fluoride values below $0.05 \mu \mathrm{g} \mathrm{F} / \mathrm{mL}$, which is the electrode sensitivity limit for the used dosing technique. Concentrations ranging from 0.5 to $0.6 \mu \mathrm{g} \mathrm{F} / \mathrm{mL}$ were recorded in the samples collected in neighbourhoods connected to the Water Treatment Station, which have benefited from water fluoridation uninterruptedly since 1997.

Socio-economic and demographic characteristics and habits related to oral health according to exposure to fluoridated water at the ages of 5 and 12 years are shown in Table 1 . Regarding the oral health habits of 5-year-olds, there was a difference between the groups in relation to the type of toothpaste and who brushed the children's teeth $(p<0.05)$. There was no difference among the groups of 12-year-olds ( $p>0.05)$. 
Table 1 - Socioeconomic and demographic characteristics and habits related to oral health in groups according to exposure to fluoridated water at the ages of five and 12 years.

\begin{tabular}{|c|c|c|c|c|c|c|c|c|c|c|}
\hline \multirow{4}{*}{ Variables } & \multicolumn{4}{|c|}{ Age 5} & \multicolumn{6}{|c|}{ Age 12} \\
\hline & \multirow{2}{*}{\multicolumn{2}{|c|}{$\begin{array}{c}F W \\
(n=161)\end{array}$}} & \multirow{2}{*}{\multicolumn{2}{|c|}{$\begin{array}{c}\text { NFW } \\
(n=169)\end{array}$}} & \multirow[t]{3}{*}{$p$} & \multirow{2}{*}{\multicolumn{2}{|c|}{$\begin{array}{c}\text { FW } \\
(n=178)\end{array}$}} & \multirow{2}{*}{\multicolumn{2}{|c|}{$\begin{array}{c}\text { NFW } \\
(n=184)\end{array}$}} & \multirow[t]{3}{*}{$p$} \\
\hline & & & & & & & & & & \\
\hline & $n$ & $\%$ & $n$ & $\%$ & & $\mathrm{n}$ & $\%$ & $n$ & $\%$ & \\
\hline \multicolumn{11}{|l|}{ Sex } \\
\hline Male & 83 & 51.6 & 94 & 55.6 & & 91 & 51.1 & 82 & 44.6 & \\
\hline Female & 78 & 48.4 & 75 & 4.4 & 0.459 & 87 & 48.9 & 102 & 55.4 & 0.212 \\
\hline \multicolumn{11}{|c|}{ Mother's education (years) } \\
\hline$\geq 8$ & 49 & 30.4 & 67 & 39.6 & & 79 & 44.4 & 92 & 50 & \\
\hline $9-11$ & 105 & 65.2 & 90 & 53.3 & 0.079 & 93 & 52.2 & 86 & 46.7 & 0.559 \\
\hline$>11$ & 7 & 4.4 & 12 & 7.1 & & 6 & 3.4 & 6 & 3.3 & \\
\hline \multicolumn{11}{|l|}{ Fam ily monthly income* } \\
\hline$<1$ & 110 & 68.3 & 26 & 74.6 & & 117 & 65.7 & 131 & 71.2 & \\
\hline $1-2$ & 51 & 31.7 & 43 & 25.4 & 0.210 & 61 & 34.2 & 53 & 28.8 & 0.297 \\
\hline \multicolumn{11}{|c|}{ Brushing frequency(times/day) } \\
\hline 1 & 19 & 11.8 & 29 & 17.2 & & 17 & 9.6 & 24 & 13 & \\
\hline 2 & 90 & 55.9 & 76 & 45 & 0.116 & 68 & 38.2 & 81 & 44 & 0.185 \\
\hline $3+$ & 52 & 32.3 & 64 & 37.8 & & 93 & 52.2 & 79 & 43 & \\
\hline \multicolumn{11}{|l|}{ Type of toothpaste } \\
\hline Non fluoridated & 7 & 4.3 & 6 & 3.5 & & 2 & 1.1 & 2 & 1.1 & \\
\hline Child fluoridated & 85 & 52.8 & 65 & 38.5 & 0.022 & 13 & 7.3 & 19 & 10.4 & 0.589 \\
\hline Adult fluoridated & 69 & 42.9 & 98 & 58 & & 163 & 91.6 & 162 & 88.5 & \\
\hline \multicolumn{11}{|l|}{ Who brushed? } \\
\hline Parents & 47 & 29.2 & 44 & 26.1 & & 20 & 11.2 & 20 & 10.9 & \\
\hline Child & 39 & 24.2 & 67 & 39.6 & 0.009 & 140 & 78.7 & 142 & 77.2 & 0.854 \\
\hline Child and some adult & 75 & 46.6 & 58 & 34.3 & & 18 & 10.1 & 22 & 11.9 & \\
\hline \multicolumn{11}{|c|}{ Amount of toothpaste (bristles) } \\
\hline $1 / 3$ & 46 & 28.6 & 51 & 30.2 & & 17 & 9.6 & 15 & 8.2 & \\
\hline $2 / 3$ & 73 & 45.3 & 83 & 49.1 & 0.511 & 87 & 48.9 & 81 & 44 & 0.484 \\
\hline $3 / 3$ & 42 & 26.1 & 35 & 20.7 & & 74 & 41.6 & 88 & 47.8 & \\
\hline \multicolumn{11}{|c|}{ Sugar ingestion (times/day) } \\
\hline$\geq 3$ & 103 & 64 & 110 & 65.1 & & 135 & 75.8 & 123 & 66.8 & \\
\hline$<3$ & 58 & 36 & 59 & 34.9 & 0.833 & 43 & 24.2 & 61 & 33.2 & 0.059 \\
\hline \multicolumn{11}{|l|}{ Visit to the dentist } \\
\hline Yes & 83 & 51.6 & 74 & 43.8 & & 148 & 83.1 & 152 & 82.6 & \\
\hline No & 78 & 48.4 & 95 & 56.2 & 0.158 & 30 & 16.9 & 32 & 17.4 & 0.892 \\
\hline
\end{tabular}

Table 2 shows the prevalence and severity of dental caries at 5 and 12-years-old according to exposure to fluoridated water. The prevalence was higher in the 5 -year-olds $(p<0.001)$ and 12-yearolds $(p=0.009)$ of the NFW group. Regarding severity, the lowest mean dmft and DMFT indexes were found in schoolchildren of the FW group $(p<0.001)$. The reduction percentage was $56.7 \%$ at 5 years and $41.8 \%$ at 12 years.

Table 2. Prevalence and severity of dental caries at five and 12 years in groups according to exposure to fluoridated water.

\begin{tabular}{lccc}
\hline \multicolumn{2}{c}{ Groups } \\
\hline \\
Age $5 \mathrm{dmft} \neq 0 \mathrm{n}(\%)$ & FW & $(\mathrm{n}=169) 106(62.7)$ & $\mathrm{p}$ \\
Mean dmft $( \pm \mathrm{SD})$ & $(\mathrm{n}=161) 65(40.4)$ & $3.54( \pm 4.10)$ & $<0.001$ \\
Decayed & $1.53( \pm 2.47)$ & $3.02( \pm 3.68)$ & $<0.001$ \\
Missing & $1.22( \pm 2.13)$ & $0.09( \pm 0.45)$ & 0.072 \\
Filled & $0.02( \pm 0.19)$ & $0.43( \pm 1.11)$ & 0.169 \\
Age 12 & $0.28( \pm 0.78)$ & $(\mathrm{n}=184)$ & 0.009 \\
DMFT $\neq 0 \mathrm{n}(\%)$ & $(\mathrm{n}=178)$ & $123(66.8)$ & $<0.001$ \\
Mean DMFT $( \pm \mathrm{SD})$ & $95(53.4)$ & $2.63( \pm 3.02)$ & $<0.001$ \\
Decayed & $1.53( \pm 1.81)$ & $2.08( \pm 2.73)$ & 0.079 \\
Missing & $1.06( \pm 1.48)$ & $0.07( \pm 0.28)$ & 0.752 \\
Filled & $0.02( \pm 0.02)$ & $0.49( \pm 1.10)$ & \\
\hline
\end{tabular}

${ }^{*} \mathrm{sd}=$ standard deviation. Categorical variable: chi-square test. Quantitative variable: T-test. 
The association between dental caries experience and socio-economic factors and habits related to oral health in 5-year-olds is described in Table 3. Children from NFW were 2.86 times (OR $=2.86,95 \%$ $\mathrm{Cl}=1.71-4.75)$ more likely to have tooth decay than those from FW. Children who brushed their teeth alone were more likely to experience caries $(\mathrm{OR}=1.92 \mathrm{Cl} 1.00-3.70)$. Factors associated with a lower caries experience were: female sex; higher mother educational level; low intake of sugar; and children not consulting the dentist $(p<0.05)$.

Table 3 - Association between dental caries experience and socioeconomic factors and habits related to oral health in five-yearolds.

\begin{tabular}{|c|c|c|c|c|c|c|c|c|}
\hline \multirow{3}{*}{ Variables } & \multicolumn{8}{|c|}{$\mathrm{dmft}$} \\
\hline & \multirow[b]{2}{*}{$=0 \mathrm{n}(\%)$} & \multirow[b]{2}{*}{$\geq 1 \mathrm{n}(\%)$} & \multirow[b]{2}{*}{ OR } & \multirow[b]{2}{*}{$\mathrm{Cl} 95 \%$} & \multicolumn{4}{|c|}{ Multiple analysis } \\
\hline & & & & & $p$ & OR & $\mathrm{Cl} 95 \%$ & $p$ \\
\hline \multicolumn{9}{|l|}{ Groups } \\
\hline FW & $96(59.6)$ & $65(40.4)$ & 1 & & & 1 & & \\
\hline NFW & $63(37.3)$ & $106(62.7)$ & 2.48 & $1.59-3.87$ & $<0.001$ & 2.86 & $1.71--4.75$ & $<0.001$ \\
\hline \multicolumn{9}{|l|}{ Sex } \\
\hline Male & $78(44.1)$ & $99(55.9)$ & 1 & & & 1 & & \\
\hline Female & $81(52.9)$ & $72(47.1)$ & 0.70 & $0.45-1.08$ & 0.108 & 0.54 & $0.32-0.90$ & 0.019 \\
\hline \multicolumn{9}{|c|}{ Mother's education (years) } \\
\hline$\geq 8$ & $44(37.9)$ & $72(62.1)$ & 1 & & & 1 & & \\
\hline $9-11$ & $105(53.8)$ & $90(46.2)$ & 0.52 & $0.32-0.83$ & & 0.49 & $0.28-0.85$ & 0.012 \\
\hline \multicolumn{8}{|c|}{ Who brushed? } & 0.028 \\
\hline Parents & $47(51.6)$ & $44(48.4)$ & 1 & & & 1 & & \\
\hline Child & $39(36.8)$ & $67(63.2)$ & 1.83 & $1.03-3.24$ & & 1.92 & $1.00-3.70$ & 0.049 \\
\hline Child/adult & $73(54.9)$ & $60(45.1)$ & 0.87 & $0.51-1.49$ & 0.015 & 1.20 & $0.65-2.24$ & 0.552 \\
\hline \multicolumn{9}{|c|}{ Sugar ingestion (times/day) } \\
\hline$\geq 3$ & $79(37.1)$ & $134(62.9)$ & 1 & & & 1 & & \\
\hline$<3$ & $80(68.4)$ & $37(31.6)$ & 0.23 & $0.16-0.44$ & $<0.001$ & 0.20 & $0.12-0.35$ & $<0.001$ \\
\hline \multicolumn{9}{|c|}{ Visit to the dentist } \\
\hline Yes & $63(40.1)$ & $94(59.9)$ & 1 & & & 1 & & \\
\hline No & $96(55.5)$ & $77(44.5)$ & 0.53 & $0.34-0.83$ & 0.005 & 0.31 & $0.18-0.54$ & $<0.001$ \\
\hline
\end{tabular}

Bivariate analysis using chi-square test. Multiple analysis controlled by socioeconomic and demographic characteristics: sex, mother's education, and family income. Model adjusted by Hosmer-Lemeshow test $(p=0.403)$

In Table 4 the association between dental caries experience and socio-economic factors and habits related to oral health in 12-year-olds is described. Adolescents from NFW were 1.95 times $(\mathrm{OR}=1.95$, $95 \% \mathrm{Cl}=1.24-3.05)$ more likely to have tooth decay than those from FW. The association of dental caries with female patients $(O R=1.74,95 \% \mathrm{Cl}=1.12-2.71)$ was observed, and low sugar intake was a protective factor against caries $(\mathrm{OR}=0.35,95 \% \mathrm{Cl}=0.21-0.57)$.

Table 4 - Association between dental caries experience and socioeconomic factors and habits related to oral health in 12-yearolds.

\begin{tabular}{|c|c|c|c|c|c|c|c|c|}
\hline \multirow{3}{*}{ Variables } & \multicolumn{8}{|c|}{ DMFT } \\
\hline & & & & & & \multicolumn{3}{|c|}{ Multiple analysis } \\
\hline & $=0 \mathrm{n}(\%)$ & $\geq 1 \mathrm{n}(\%)$ & OR & $\mathrm{Cl} 95 \%$ & $\mathrm{p}$ & OR & $\mathrm{Cl} 95 \%$ & $p$ \\
\hline \multicolumn{9}{|l|}{ Groups } \\
\hline FW & $85(46.6)$ & $93(53.4)$ & 1 & & & 1 & & \\
\hline NFW & $62(33.2)$ & $122(66.8)$ & 1.76 & $1.15-2.69$ & 0.009 & 1.95 & $1.24-3.05$ & 0.003 \\
\hline \multicolumn{9}{|l|}{ Sex } \\
\hline Male & $82(46.8)$ & $91(53.2)$ & 1 & & & 1 & & \\
\hline Female & $65(33.3)$ & $124(66.7)$ & 1.76 & $1.15-2.69$ & 0.009 & 1.74 & $1.12-2.71$ & 0.013 \\
\hline \multicolumn{9}{|c|}{ Sugar ingestion(times/day) } \\
\hline$\geq 3$ & 88(33.3) & $170(66.7)$ & 1 & & & 1 & & \\
\hline$<3$ & $59(55.8)$ & $45(44.2)$ & 0.39 & $0.24-0.63$ & $<0.001$ & 0.35 & $0.21-0.57$ & $<0.001$ \\
\hline
\end{tabular}

Bivariate analysis using chi-square test. Multiple analysis controlled by socioeconomic and demographic characteristics: gender, mother's education, and family income. Model adjusted by hosmer-lemeshow test $(p=0.968)$

No dental fluorosis was observed in the 5-year-old children of either group. The association between dental fluorosis and socio-economic demographic factors and habits related to oral health in 12-year- 
olds is described in Table 5. In the FW, $41.6 \%$ presented very mild/mild fluorosis and $18 \%$ presented moderate fluorosis. In the NFW group, the prevalence of very mild/mild fluorosis was $15.2 \%$, and $3.3 \%$ of individuals presented moderate fluorosis $(p<0.001)$.

Table 5 - Association between dental fluorosis and socioeconomic demographic factors and habits related to oral health in 12-year-olds.

\begin{tabular}{|c|c|c|c|c|}
\hline \multirow[t]{2}{*}{ Variables } & \multicolumn{3}{|c|}{ Dental Fluorosis } & \multirow[b]{2}{*}{$p^{*}$} \\
\hline & Absent n (\%) & Very mild / mild n (\%) & Moderate $\mathrm{n}(\%)$ & \\
\hline \multicolumn{5}{|l|}{ Groups } \\
\hline FW & $72(40.4)$ & $74(41.6)$ & $32(18.0)$ & \\
\hline NFW & $150(81.5)$ & $28(15.2)$ & $6(3.3)$ & $<0.001$ \\
\hline \multicolumn{5}{|l|}{ Sex } \\
\hline Male & $101(58.4)$ & $52(30.1)$ & $20(11.5)$ & \\
\hline Female & $121(64.0)$ & $50(26.5)$ & $18(9.5)$ & 0.538 \\
\hline \multicolumn{5}{|l|}{ Mother's education (years) } \\
\hline$\geq 8$ & 107(62.6) & $47(27.5)$ & $17(9.9)$ & \\
\hline $9-11$ & 107(59.8) & $52(29.1)$ & $20(11.1)$ & \\
\hline$>11$ & $8(66.7)$ & $3(25.0)$ & $1(8.3)$ & 0.976 \\
\hline \multicolumn{5}{|l|}{ Family income (BS) } \\
\hline$<1$ & $151(60.9)$ & $71(28.6)$ & $26(10.5)$ & \\
\hline $1-2$ & $71(62.8)$ & $30(26.5)$ & $12(10.7)$ & 0.919 \\
\hline \multicolumn{5}{|c|}{ Brushing frequency (time/day) } \\
\hline 1 & $28(68.3)$ & $9(22.0)$ & $4(9.7)$ & \\
\hline 2 & $89(59.7)$ & $42(28.2)$ & $18(12.1)$ & \\
\hline$\geq 3$ & 105(61.0) & $51(29.7)$ & $16(9.3)$ & 0.791 \\
\hline \multicolumn{5}{|l|}{ Type of toothpaste } \\
\hline \multirow[t]{3}{*}{ Non fluoridated } & $2(50.0)$ & $2(50.0)$ & $0(0.0)$ & \\
\hline & $19(59.4)$ & $12(37.5)$ & $1(3.1)$ & \\
\hline & $200(61.5)$ & $88(27.1)$ & $37(11.4)$ & 0.378 \\
\hline \multicolumn{5}{|l|}{ Who brushed? } \\
\hline Parents & $21(52.5)$ & $16(40.0)$ & $3(7.5)$ & \\
\hline Child & $177(62.8)$ & $77(27.3)$ & $28(9.9)$ & \\
\hline Child and some adult & $24(60.0)$ & $9(22.5)$ & $7(17.5)$ & 0.246 \\
\hline \multicolumn{5}{|c|}{ Amount of toothpaste (bristle) } \\
\hline $1 / 3$ & $22(68.7)$ & 10(31.3) & $0(0.0)$ & \\
\hline $2 / 3$ & $103(61.3)$ & $50(29.8)$ & $15(8.9)$ & \\
\hline $3 / 3$ & $97(59.9)$ & $42(25.9)$ & $23(14.2)$ & 0.149 \\
\hline \multicolumn{5}{|l|}{ Sugar ingestion (time/day) } \\
\hline$\geq 3$ & 73(57.8) & $81(31.4)$ & $28(10.8)$ & \\
\hline$<3$ & $149(70.2)$ & $81(20.2)$ & 10(9.6) & 0.071 \\
\hline \multicolumn{5}{|l|}{ Visit to the dentist } \\
\hline Yes & $181(60.3)$ & $88(29.3)$ & $31(10.3)$ & \\
\hline No & $41(66.1)$ & $14(22.6)$ & $7(11.3)$ & 0.561 \\
\hline
\end{tabular}

${ }^{*}$ Chi-square test.

Adolescents in the FW group were five and 11 times more likely than those of NFW to develop very mild / mild ( $O R=5.45,95 \% \mathrm{Cl}=3.23-9.19)$ and moderate fluorosis $(\mathrm{OR}=11.11,95 \% \mathrm{Cl}=4.43-27.87)$, respectively, which is described in Table 6.

Table 6 - Associated factors for the presence of very mild/mild and moderate fluorosis among 12-year-olds.

\begin{tabular}{|c|c|c|c|c|c|c|}
\hline \multirow[t]{2}{*}{ Variables } & \multicolumn{3}{|c|}{ Very mild/mild fluorosis } & \multicolumn{3}{|c|}{ Moderate fluorosis } \\
\hline & OR & $\mathrm{Cl} 95 \%$ & $p$ & OR & $\mathrm{Cl} 95 \%$ & $p$ \\
\hline Group & & & & & & \\
\hline FW & 5.45 & $3.23-9.19$ & $<0.001$ & 11.11 & $4.43-27.87$ & $<0.001$ \\
\hline NFW & 1 & & & 1 & & \\
\hline
\end{tabular}

Logistic regression. Multiple analysis controlled by socioeconomic and demographic characteristics: sex, mother's education, and family income. Model adjusted by Desviance test $(p=0,088)$.

\section{Discussion}

Children and adolescents, who consumed fluoridated water, had a lower prevalence and severity of dental caries, despite the use of fluoridated toothpaste. Moreover, adolescents aged 12 who ingested 
fluoridated water had a higher risk of developing fluorosis. Both groups of children and adolescents lived in the suburbs of the city, with similar socio-economic and demographic characteristics. This similarity is fundamental for the comparison, as there is evidence of a correlation between low socio-economic levels and an increase in the prevalence of caries (13). A similar result was found in a scenario of low dental caries prevalence (14), although the effect of water fluoridation in tooth decay is more relevant among vulnerable populations (15).

Despite the reduction in the prevalence and severity of dental caries in several countries, this disease still remains an important public health problem (16). In this study, most children and adolescents examined had at least one decayed tooth, which indicates the absence of assistance or use of service. In addition to the presence of caries experience, it is important to evaluate the severity with which the disease manifests itself. Even with the use of fluoridated toothpaste in both groups, we observed a difference between the mean $\mathrm{dmft}$ and DMFT indexes of the FW group when compared to the NFW group. These differences are greater than those observed by Narvai et al (17), who evaluated data referring to populations representing capital cities obtained in the National Oral Health Surveys conducted in Brazil in 2003 and 2010.

At the two ages evaluated in the present study, the indexes that measured the severity of the disease were predominantly composed of decayed teeth. There was a difference in this component between the FW and NFW groups. Children and adolescents from low-income families have an increased risk of untreated dental caries due to difficulties in accessing health goods and services. Among 5-year-old children, those who did oral hygiene alone were more likely to have decayed teeth, which corroborates with the findings of Lima et al (18). Children living in areas with fluoridated water received more help in performing brushing than residents of non-fluoridated areas, which may justify a higher prevalence of caries in the latter group. This result reinforces the need for parents or caregivers to assist in the toothbrushing process, since children at this age are still developing their motor skills.

The reduction in dental caries rates has awakened the attention of dentists with regard to dental fluorosis. The degree of fluorosis will depend on the amount of fluoride ingested and the time of ingestion, as it is caused by chronic fluoride intake (9). In this study, fluorosis rates were lower than those observed in Teresina with a representative sample of the municipality that covered all regions (12). The occurrence of mild dental fluorosis is expected in areas with water fluoridation and may even serve as a parameter for the evaluation of the fluoridation system $(12,13)$. When the alteration is classified as very $\mathrm{mild} / \mathrm{mild}$, there is no aesthetic implication, and it is often not perceived by the population and does not influence the quality of life related to oral health (19). It is possible to suggest from the results of this study that the prevalence of dental fluorosis in 5 -year-olds is not influenced by water fluoridation, since no change was observed in these children in either group.

Studies carried out in the same city showed that water made the greatest contribution to fluoride intake in children with high socioeconomic levels (20) while fluoridated toothpaste was the main source for children of low socio-economic status (21). These data justify the presence of some degree of fluorosis in this study in 12-year-old schoolchildren in the NFW group. This finding can also be attributed to the 'halo effect', which refers to the production of food and beverages in regions with fluoridated water that are consumed in regions without fluoridation and expose this population to an additional source of fluoride (22).

Considering that the main risk factors for dental fluorosis are related to fluoridated toothpaste and brushing habits, even among communities with water fluoridation (23), it is important to point out the need to promote educational actions regarding its correct use. Actions with the aim of gaining the maximum benefit in the control of dental caries and minimizing the risks of dental fluorosis, such as the use of toothpaste with a conventional concentration of $F$ in small quantities (7), are highly recommended.

The 'halo effect' must be taken into consideration in our findings for non-fluoridated areas, because this effect tends to mask the influence of water fluoridation on caries prevention or induces light levels of fluorosis in areas without the benefit. This methodological design included two social spaces that can be compared, with simultaneous data collection, compatible with the concept of community testing, paired by similarity of their characteristics as social spaces, so that only exposure or not to the fluoridation of public water supply, could distinguish them (14). Due to the proximity between the paired neighborhoods, residents of the non-fluoridated neighborhoods might have access to water and derivatives prepared with fluoridated water from neighboring fluoridated areas. Therefore, if any effect is reported, the true one is supposed to be larger and this may be considered one of the limitations of the present study. Furthermore, our results must be extrapolated to populations of low socio-economic profiles. 
Another limitation of this study is that there is no exact information on the fluoride concentration to which individuals have been exposed in the past, even though attempts to minimize these limitations by performing more sensitive statistical tests to identify associations of variables were tried. The Cochrane review method considers randomized clinical trials as the gold standard of evidence and automatically rates common methods for evaluating public health interventions as low. However, randomized trials are usually not feasible for interventions at the population level. The authors noted this gap in their evidence grading system and that the evidence pointed in the same direction of fluoridation reducing tooth decay (11).

Most allegations about the negative aspects of water fluoridation, for example, that it causes diseases, are based on transversal studies and not on cause-effect studies (9). Research with robust designs shows that it only increases the prevalence of dental fluorosis, which does not impact the quality of life of affected individuals $(9,24)$. Nevertheless, cross-sectional studies are designs that can be very useful in supporting decision-making involving public policy (14). Fluoridated water should still be considered in some countries where people are not adequately exposed to the preventive effect of fluoride. The challenge for countries is to increase the potential benefit of fluoride by adapting their policies on its use. This initiative can help to break the disparities in dental caries prevalence and severity, especially in developing countries (25).

In conclusion, children and adolescents who consumed fluoridated water presented lower prevalence and severity of dental caries compared to those who used only fluoridated toothpaste as a source of fluoride. The association between fluoridated toothpaste use and water fluoridation increased the risk of development of very mild / mild and moderate fluorosis in 12-year-old adolescents, but not in 5-year-old children.

\section{Conflict of interest}

The authors hereby certify they have no conflict of interests.

\section{Acknowledgements}

The authors express their gratitude to the participants and their parents, the schools and the Municipal Department of Education and Culture, who allowed the study to be carried out in educational institutions. The authors would like to thank all undergraduate students who assisted as note takers during the data collection: Carolina Nascimento Sousa, Geovanna Peres de Sousa and Sarah Inacio Furtado Silva. The authors also thank the Coordination of Improvement of Higher Education Personnel (Capes) for the support and funding of this research.

\section{Resumo}

Este estudo transversal avaliou a prevalência e severidade de cárie dentária e fluorose em crianças de 5 anos e adolescentes de 12 anos usuários de dentifrício fluoretado, em áreas com e sem água fluoretada. Os responsáveis pelas crianças e adolescentes responderam questionários para determinação de caracteristicas socioeconômicas e demográficas e hábitos relacionados à saúde. Os indivíduos foram examinados e a cárie e a fluorose foram mensuradas pelos índices ceo-d / CPOD e TF, respectivamente. Foram realizadas análises descritivas, bivariadas e de regressão logística $(p<0,05)$. Dos 692 participantes, 47,7\% tinham 5 anos e 52,3\% tinham 12 anos. A média de ceod / CPOD em crianças de 5/12 anos dos grupos de exposto e não exposto à água fluoretada foi $1,53( \pm 2,47)$ e $3,54( \pm 4,10) / 1,53( \pm 1,81)$ e 3,54 $( \pm 3,82)$, respectivamente. Crianças $(O R=2,86$, IC $95 \%=1,71-4,75)$ e adolescentes $(O R=1,95$, IC $95 \%$ $=1,24-3,05)$ que não consumiram água fluoretada tiveram maior experiência de cárie. Entre os adolescentes, houve associação entre a água fluoretada e a prevalência de fluorose muito leve / leve (OR $=5,45$, IC 95\%: 3,23-9,19) e fluorose moderada (OR = 11,11, IC 95\% = 4,43-27,87). Crianças e adolescentes que consumiram água fluoretada apresentaram menor prevalência e severidade de cárie dentária em comparação com aqueles que usaram apenas dentifrício fluoretado como fonte de flúor. Houve uma associação entre a fluoretação da água e fluorose muito leve / leve e moderada em adolescentes. 


\section{References}

1. Petersen PE; Bourgeois D; Ogawa H; Estupinan-Day S; Ndiaye C. The global burden of oral diseases and risks to oral health. Bull World Health Organ. 2005, 83, 661-9.

2. McDonagh MS; Whiting PF; Wilson PM; Sutton AJ; Chestnutt I; Cooper J; Misso K; Bradley M; Treasure E; Kleijnen J. Systematic review of water fluoridation. BMJ. 2000,321, 855-9.

3. Yeung CA. A systematic review of the efficacy and safety of fluoridation. Evid Based Dent. 2008, 9,39-43.

4. Cho HJ; Jin BH; Park DY; Jung SH; Lee HS; Paik DI et al. Systemic Effect of Water Fluoridation on Dental Caries Prevalence. Community Dent Oral Epidemiol .2014, 42,341-8.

5. Dalla Nora A; Dalmolin A; Gindri LD; Moreira CHC; Alves LS; Zenkner JEDA. Oral health status of schoolchildren living in rural and urban areas in southern Brazil. Braz Oral Res. 2020,34,e060.

6. Cheng KK; Chalmers I; Sheldon TA. Adding fluoride to water supplies. BMJ. 2007, 335, 699-702.

7. Whelton, HP; Spencer, AJ; Do, LG; Rugg-Gunn, AJ. Fluoride Revolution and Dental Caries: Evolution of Policies for Global Use. Journal of Dental Research. 2019;98(8), 837-846.

8. Cury JA; Ricomini-Filho AP; Berti FLP; Tabchoury CP. Systemic Effects (Risks) of Water Fluoridation. Braz Dent J. 2019, 30, 421-428.

9. Cury JA; Tenuta LMA. Evidence-based recommendation on toothpaste use. Braz Oral Res. 2014,28, 1-7.

10. Aoun A; Darwiche F; Hayek SA; Doumit J. The Fluoride Debate: The Pros and Cons of Fluoridation. Prev Nutr Food Sci .2018;23(3):171-180.

11. Iheozor-Ejiofor Z; Worthington HV; Walsh T; O'Malley L; Clarkson JE; Macey R et al. Water fluoridation for the prevention of dental caries. Cochrane Database Syst Rev .2015,6.

12. Moura MS; Barbosa PR; Nunes-Dos-Santos DL; Dantas-Neta NB; Moura LF; De Lima MD. Epidemiological surveillance of dental fluorosis in a tropical climate city with fluoridated public water supply. Ciên Saúde Colet. 2016,21,1247-1254.

13. Peres KG; Peres MA; Barbato PR; Hofelmann DA. Access to fluoridated water and adult dental caries: a natural experiment. J Dent Res .2016,95,868-874.

14. Cruz MGB; Narvai PC. Caries and fluoridated water in two Brazilian municipalities with low prevalence of the disease. Rev Saude Publica. 2018,52,28.

15. Blinkhorn AS; Byun R; Mehta P; Kay M. A 4-year assessment of a new water-fluoridation scheme in New South Wales, Australia. Int Dent J .2015, 65, 156-163.

16. Barbato PR; Peres MA. Contextual and individual indicators associated with the presence of teeth in adults. Rev Saúde Pública. 2015,49,27.

17. Narvai PC; Frias AC; Fratucci MV; Antunes JL; Carnut L; Frazão P. Fluoridation of water in Brazilian capitals at the beginning of the 21st century: the effectiveness in question. Saúde Debate. 2014,38,562-571.

18. Lima CV; Pierote JJ; Neta HA; Lima MD; Moura LF; Moura MS. Caries, toothbrushing habits, and fluoride intake from toothpaste by Brazilian children according to socioeconomic status. Pediatr Dent $.2016,38,305-310$.

19. Moimaz AS; Saliba O; Marques LB; Garbin CA; Saliba NA. Dental fluorosis and its influence on children's life. Braz Oral Res. 2015,29,1-7.

20. Oliveira PFT; Cury JA; Lima CV; Vale GC; Lima MDM; Moura LFAD et al. Is the fluoride intake by diet and toothpaste in children living in tropical semi-arid city safe?. Braz Oral Res. 2018,32, e26.

21. Lima CV; Cury JA; Vale GC; Lima MD; Moura LF; Moura MS. Total fluoride intake by children from a tropical Brazilian city. Caries Res .2015, 49,640-646.

22. Carey CM. Focus on fluorides: update on the use of fluoride for the prevention of dental caries. Journal of Evidence-based dental practice. 2014, 14,95-102.

23. Celeste RK; Luz PB. Independent and Additive Effects of Different Sources of Fluoride and Dental Fluorosis. Pediatric Dentistry .2016, 38, 233-238.

24. Kim FM; Hayes C; Burgard SL; Kim HD; Hoover R; Douglass CW; Couper D. A Case-Control Study of Fluoridation and Osteosarcoma. J Dent Res. 2020, 99, 1157-1164.

25. Ndagire $B$, Kutesa $A$; Ssenyonga $R$; Kiiza HM; Nakanjako $D$; Rwenyonyi CM. Prevalence, Severity and Factors Associated with Dental Caries Among School Adolescents in Uganda: A Cross-Sectional Study. Braz. Dent. J. 2020 , 31( 2 ), 171-178. 